\title{
A IMPORTÂNCIA DO LÚDICO NO ENSINO DA MATEMÁTICA E ESTATÍSTICA NO ENSINO FUNDAMENTAL
}

\author{
Edmeire Aparecida Fontana \\ Universidade Federal do Triângulo Mineiro, Uberaba - MG \\ Bolsista Coordenação de Aperfeiçoamento de Pessoal de Nível Superior (CAPES) \\ edmeirematematica@gmail.com
}

A pesquisa teve como objetivo geral: Fazer um estudo teórico sobre a importância de relacionar teoria e prática no trabalho pedagógico, por meio das atividades lúdicas e jogos matemáticos para a melhoria do processo de ensino e aprendizagem da Matemática e Estatística no Ensino Fundamental com a perspectiva de servir de apoio para motivar os professores de matemática a aplicar diversas metodologias de ensino em sala de aula. Percebe-se que há muitos desafios a serem superados pelo professor no Ensino da Matemática e Estatística, no entanto, faz-se necessário a busca de novos conhecimentos através de formação continuada, a fim de superar as dificuldades encontradas na sala de aula. A busca por diversas metodologias de ensino pode ser uma medida adotada pelo professor educador com o intuito de facilitar a aprendizagem do aluno $e$ prepará-lo para exercer seu papel de cidadão responsável, crítico e reflexivo.

The research had as general aim: To make a theoretical study about the importance of relate theory and practice in the pedagogical work, through ludic activities and mathematical games to the improvement of the teaching and learning process of Mathematics and Statistics of the Ensino Fundamental with the perspective of serving as support to motivate the mathematics teachers to apply several teaching methodologies in the classroom. We can notice that there are several challenges to be overcome by the teacher in Mathematics and Statistics Teaching; however, it's necessary to look for new knowledge through continuous formation, in order to overcome the difficulties found in the classroom. The search for different teaching methodologies can be a measure adopted by the teacher with the intention of facilitate the student's learning and prepare him/her to practice his/her role as responsible, critic and reflective citizen.

\section{INTRODUÇÃO}

A presente pesquisa é um estudo teórico sobre a importância do lúdico, e da junção da teoria com a prática, utilizando os jogos como ferramentas metodológicas de grande valia no processo de ensino e aprendizagem da Matemática e Estatística.

Conforme Borin (2002), os jogos matemáticos oferecem uma forma muito mais abrangente de trabalhar em sala de aula, já que o campo disponível a se explorar é amplo. Essas atividades com jogos vão além do conhecimento de retenção e aquisição de conteúdos, visto que, os relacionamentos entre aluno-aluno e aluno-professor, envolvem outros aspectos importantes para a formação do aluno, tais como: respeito, disciplina, ética, linguagem, raciocínio, entre outros.

A resolução de problemas é um dos principais fatores que podem ser envolvidos nos jogos, o qual leva o aluno a refletir sobre suas ações e a de seus colegas. Tornando essas atividades frequentes em sala de aula, espera-se que o aluno seja capaz de relacionar os problemas enfrentados nos jogos com os de sua realidade. Unir teoria à prática possibilita o professor observar, analisar e interferir, quando necessário, nas atitudes dos alunos durante o processo do jogo, contribuindo assim, para a construção de seu conhecimento e crescimento pessoal.

Nota-se no ambiente escolar, que os professores não se encontram preparados para a utilização de metodologias de ensino, as quais viabilizam sua prática pedagógica de modo a favorecer a melhoria do processo ensino e aprendizagem da Matemática. A formação continuada é um meio, pelo qual, o professor pode-se inserir para aperfeiçoar, atualizar e refletir sobre sua prática educativa, buscando conhecimento e novas metodologias de ensino, a fim, de tornar suas aulas mais interessantes, motivadoras e desafiadoras para o aluno.

Contribuir para o progresso do aluno, para que este seja capaz de enfrentar os problemas futuros de maneira ativa e inteligente, é um dos desafios do professor educador. A cidadania, o conhecimento, a responsabilidade, a ética, os valores, são bens incalculáveis que o professor pode oferecer a seu aluno de forma simples no dia a dia do ambiente escolar. E isso pode ser explorado

In: M.A. Sorto (Ed.), Advances in statistics education: developments, experiences and assessments. Proceedings of the Satellite conference of the International Association for Statistical Education (IASE), July 2015, Rio de Janeiro, Brazil. 
por meio das atividades lúdicas e dos jogos matemáticos, desde que, as aulas sejam bem preparadas e avaliadas constantemente, para que o professor leve em conta a reflexão sobre sua prática educativa.

Este trabalho centra-se na pesquisa bibliográfica. A pesquisa teve como objetivo geral, fazer um estudo teórico sobre a importância de relacionar teoria e prática no trabalho pedagógico. E também tem o objetivo de servir de apoio para motivar os professores de Matemática a aplicar diversas metodologias e novas tecnologias de ensino na sala de aula, por meio, das atividades lúdicas e dos jogos matemáticos, contribuindo, para a melhoria do processo de ensino e aprendizagem de Matemática e Estatística. Os principais autores pesquisados para o desenvolvimento dessa pesquisa foram Dienes (1975), Borin (2002), os Parâmetros Curriculares Nacionais - PCN (1997) de Matemática, Lopes (2008), Cazorla (2004), entre outros autores.

O assunto interpelado é o lúdico e os jogos no Ensino de Matemática e Estatística: unindo teoria e prática, no processo de aprendizagem. Assim, torna-se clara a evidência de saber utilizar os jogos matemáticos e as atividades lúdicas em sala de aula com a pretensão do desenvolvimento do conhecimento matemático e a socialização do aluno.

\section{FUNDAMENTAÇÃO TEÓRICA}

Ame a infância; estimule seus jogos, seus prazeres, seus encantadores instintos... Considere o homem no homem e a criança na criança... A natureza deseja que as crianças sejam crianças antes de serem homens. Se tentarmos inverter a ordem, produziremos frutos precoces que não terão nem maturação nem sabor, e logo estarão estragados... a infância tem seus meios próprios de ver, pensar, sentir, que lhe são convenientes; nada é menos razoável que substituir o que nos é próprio. (COURTNEY, 2006, p. 17).

O lúdico e os jogos matemáticos possibilitam uma aprendizagem divertida na infância, pois o estímulo é fundamental para o desenvolvimento da criança como um todo, ou seja, a corporeidade. Os jogos, as brincadeiras, as atividades lúdicas despertam o interesse, o movimento e a criatividade das mesmas. É importante respeitar cada etapa do desenvolvimento infantil, a fim de que se tornem adultos aptos a enfrentarem quaisquer problemas com responsabilidade.

Para Moreira (2003) "Corporeidade é voltar a viver novamente a vida, na perspectiva de um ser unitário e não dual, num mundo de valores existenciais e não apenas racionais, ou quando muito simbólicos. Corporeidade é incorporar signos, símbolos, prazeres, necessidades, através de atos ousados ou através de recuos necessários sem achar que um nega o outro. É cativar e ser cativado por outros, pelas coisas, pelo mundo, numa relação dialógica."

Segundo Dienes (1975 a), há seis etapas do processo de aprendizagem em Matemática. A primeira etapa consiste na apresentação do aluno ao meio, para que ele possa extrair certas estruturas matemáticas. Na segunda etapa, os jogos estruturados são apresentados. Há regras, objetivo e a possibilidade dos jogos serem examinados. O aluno é capaz de perceber na terceira etapa jogos que apresentam as mesmas estruturas. Na quarta etapa o aluno desenvolverá o processo de representação dos jogos, que pode ser por meio de gráficos, tabelas, sistema cartesiano, entre outros. A quinta etapa trata-se da descrição da representação dos jogos e da criação de uma linguagem para representá-lo. Por fim, na sexta etapa o aluno deve ser capaz de notar um sistema formal de uma estrutura de jogo, com demonstração, axiomas e teoremas de acordo com a descrição das propriedades no decorrer dos jogos.

As atividades lúdicas são de suma importância para o desenvolvimento afetivo, social, cognitivo, nas relações com o outro, com o meio, no processo de aprendizagem do aluno e na corporeidade. Ao brincar ou jogar o aluno está presente como um todo, é o seu corpo que expõe seus medos, suas angústias, ansiedades e frustrações. Por meio das atividades lúdicas diárias o aluno torna-se capaz de relacioná-la com a realidade, pois tem a possibilidade de assimilar soluções que usaram para resolver os problemas do jogo e das atividades lúdicas com os problemas enfrentados e presenciados corporalmente no seu dia a dia.

De acordo com Nóbrega (2010) o pensamento de Merleau-Ponty sobre a Fenomenologia como método, "o corpo, o gesto, o conhecimento sensível e os processos perceptivos são trazidos para o primeiro plano da reflexão." 
As atividades lúdicas e os jogos matemáticos são ferramentas pedagógicas que podem ser utilizadas na sala de aula com o intuito de despertar o interesse do aluno em sua totalidade e tornar a aprendizagem um processo prazeroso, tanto para o professor, quanto para o aluno.

Na pedagogia tradicional, trabalha-se exatamente em sentido inverso. Introduz um sistema formal, por meio de símbolos. Percebe-se que a criança não está apta a compreender tal sistema e por isso se lança mão de meios audiovisuais para fazê-la compreender. Isto quer dizer que, a partir da etapa de simbolismo, passa-se à etapa da representação. Descobre-se, ainda, que a criança não está apta a aplicar os conceitos, mesmo depois dos recursos audiovisuais consequentemente, torna-se necessário ensinar-lhe as aplicações na realidade. Chega-se, finalmente, à realidade, de onde se deveria ter partido. Assim, no ensino tradicional, a direção da aprendizagem é exatamente contrária à proposta [...] (DIENES, 1975 a, p. 72).

Atualmente, os professores se encontram em busca de conhecimentos de metodologias de ensino para que se tornem aptos a ministrar aulas que realmente estejam voltadas para a realidade do aluno. E de acordo com nosso estudo nota-se a importância de conhecimentos axiológicos, pois não é somente a teoria que resolverá os problemas no ambiente escolar é o valor que contribuirá para a aprendizagem significativa do corpo para a cidadania.

Rezende (1990) diz: "O homem conhece e pensa. A aprendizagem significativa consiste igualmente em adquirir conhecimentos e em aprender a pensar."

Em síntese, de acordo com Dienes (1975 b), qualquer pessoa pode criar um jogo desde que possua algum conhecimento matemático e seja capaz de seguir suas regras. No jogo matemático, como em qualquer outro tipo de jogo, pode-se apresentar regras prontas para serem aplicadas, e a maneira de expor as regras, envolve uma aprendizagem fechada. $\mathrm{Na}$ aprendizagem fechada as regras dos jogos já estão prontas e são apresentadas aos alunos antes de iniciar o jogo. No entanto, o aluno diante de um jogo pode criar as regras, assim também como se pode utilizar das regras para inventar outros jogos. Assim temos uma aprendizagem aberta.

A opção de criar as regras do jogo é mais interessante para o desenvolvimento da aprendizagem dos alunos, já que será necessário um maior envolvimento da turma para a elaboração dessas regras a fim de alcançar o objetivo desejado do jogo a ser executado. A atitude do professor em proporcionar seus alunos à participação, a movimentação e a troca de experiências é de fundamental importância para o processo de ensino e aprendizagem, além de contribuir para construção do conhecimento axiológico, interação e socialização. Entretanto, é importante que o aluno perceba que as regras e as condutas são necessárias para a organização da atividade ou jogo, assim como na sociedade em que vivemos.

Há também a percepção de que as jogadas são dependentes, assim é preciso respeitar a vez do outro para jogar. Além da interação, as atividades lúdicas proporcionam socialização e valores indispensáveis para bons relacionamentos entre indivíduos.

Segundo Huizinga (1996), não há como definir exatamente o jogo, no entanto, pode-se expor suas características. Por meio do jogo, o aluno pode expressar seus sentimentos, assim o professor observador torna-se capaz de analisar o comportamento do aluno como um todo e auxiliá-lo para enfrentar suas dificuldades.

Nóbrega (2010), assim define "O corpo não é coisa, nem idéia, o corpo é movimento, gesto, linguagem, sensibilidade, desejo, historicidade e expressão criadora."

O jogo é um instrumento capaz de contribuir para a construção do conhecimento do aluno. No entanto, para que a aprendizagem seja significativa é necessário que o professor tenha um bom planejamento de suas atividades diárias com objetivos claros e bem definidos.

[...] a introdução de jogos nas aulas de Matemática é a possibilidade de diminuir os bloqueios apresentados por muitos de nossos alunos que temem a Matemática e sentem-se incapacitados para aprendê-la. Dentro da situação de jogo, onde é impossível uma atitude passiva e a motivação é grande, notamos que, ao mesmo tempo em que estes alunos falam matemática, apresentam também um melhor desempenho e atitudes mais positivas frente a seus processos de aprendizagem. (BORIN, 2002, p. 9). 
No processo de ensino e aprendizagem a prática educativa é avaliada e reavaliada constantemente, garantindo assim, o sucesso de um trabalho proposto. A postura adotada pelo professor educador perante seus alunos está interligada a interação dos mesmos. O jogo é uma forma envolvente de conquistar o aluno na sala de aula, mesmo que, em um primeiro momento não conquiste o desejo dos alunos em participar, mas basta observar os colegas de sala se divertindo e aprendendo que logo querem jogar.

De acordo com Dienes (1975b, p.174) “....mas mesmo a matemática que as crianças em escolas podem entender somente o serão se lhes forem dadas oportunidades de explorá-la sob a orientação de professores simpáticos e entusiastas".

A Matemática e a Estatística é uma fonte ampla a ser explorada. Os jogos e as atividades lúdicas no Ensino de Matemática e Estatística permitem aos alunos a capacidade de relacionar as diversidades enfrentadas nos jogos com as dificuldades a serem enfrentadas no seu cotidiano, entretanto, para que isso aconteça é necessário um bom trabalho do professor orientador, o qual é motivador dos jogos e atividades lúdicas para que o corpo do aluno amadureça esses conhecimentos e seja capaz de relacioná-lo com a realidade em que vive.

Gal (2002) aponta que letramento estatístico é a capacidade de interpretar e avaliar criticamente informações estatísticas, levando em consideração os argumentos relacionados aos dados ou aos fenômenos apresentados em algum contexto.

Mendoza e Swift (1981) entendem que o conhecimento de Estatística e Probabilidade é necessário para a atuação do cidadão na sociedade.

Cazorla (2004) afirma que para uma cidadania plena, o pensamento estatístico é tão necessário quanto a capacidade de ler e escrever.

Assim, conforme Onuchic e Allevato (2009) a aplicação de conteúdos de Estatística no Ensino Fundamental conforme recomendam os Parâmetros Curriculares Nacionais - PCN (1997), devem ser feitos de forma crítica, com foco na leitura e interpretação de dados, e não apenas nos cálculos e na álgebra.

Neste tripé educação-estatística-cidadania, Lopes (2008) afirma que, para que o ensino de Estatística e Probabilidade contribua na educação para a efetivação desse fato, é importante que se possibilite aos alunos o confronto com problemas variados do mundo real e que eles tenham possibilidade de escolher suas próprias estratégias para solucioná-los.

[...], quando analisamos o comportamento e a atividade mental de um jogador disposto a ganhar, verificamos que a postura é a mesma de um cientista em busca de solução para um problema. Os dois, inicialmente, partem para uma experimentação ou tentativa para conhecer o que defrontam, sem muita ordem ou direção. Após essa fase, como numa investigação científica, coletam os dados que podem influenciar ou alterar as várias situações e formulam hipóteses que precisarão ser testadas. Estabelecida uma hipótese, partem para a experimentação ou jogada e observam o que acontece. Se for necessário, reformulam as hipóteses feitas e realizam nova verificação. A cada tentativa usam as conclusões obtidas e os erros cometidos para orientar as novas hipóteses até certificarem-se da resposta precisa para o problema original, o que, no caso do jogo, significa ter uma boa estratégia para vencer. (BORIN, 2002, p. 8).

O desafio do jogo está na capacidade do jogador de interpretá-lo e verificar as melhores alternativas que podem ser experimentadas e avaliadas quanto ao objetivo que o jogador deseja alcançar. Tendo base a assertiva de Borin (2002), a partir do momento que o jogador começa a formular e reformular suas hipóteses, por meio das jogadas anteriores, observando as jogadas satisfatórias e as insatisfatórias ele está utilizando o raciocínio dedutivo. Então, de acordo com cada nova jogada o aluno vai desenvolvendo sua capacidade e habilidade de deduzir quais jogadas serão possíveis de serem realizadas pelos outros jogadores a partir da jogada anterior.

Durante o avanço no jogo o aluno se imagina um ser indispensável que está desempenhando um papel importante, pois ele criativamente se transporta para as estratégias do jogo. É necessário dizer o quanto esses momentos de atividades lúdicas e jogos são extremamente importantes para o aluno em todos os aspectos, pois há o desenvolvimento da comunicação, 
linguagem, movimentação, expressão, socialização, interação, ética, além da aquisição e construção de conhecimentos.

Por meio da atividade lúdica o aluno aperfeiçoa sua criatividade. O mundo imaginado na atividade é seu mundo de descobertas, alegrias, medos, entre outros. Para o aluno a atividade lúdica se torna real, pois ele é quem dá vida ao imaginado. Isso é muito bom para seu processo de criação, pois o aluno analisa e reflete sobre quais vantagens e desvantagens ele tem para desempenhar o personagem.

A racionalidade deve reconhecer a parte de afeto, de amor e de arrependimento. A verdadeira racionalidade conhece os limites da lógica, do determinismo e do mecanicismo; sabe que a mente humana não poderia ser onisciente, que a realidade comporta mistério. Negocia com a irracionalidade, o obscuro, o irracionalizável. É não só crítica, mas autocrítica. Reconhece-se a verdadeira racionalidade pela capacidade de identificar suas insuficiências. (Morin, 2011).

O professor para trabalhar com os jogos precisa conhecer e jogar, antes de levá-los para a sala de aula e apresentá-los aos alunos, para que o professor seja capaz de orientá-los e motivá-los a enfrentar as dificuldades que os alunos apresentam no processo do jogo. Há diversos tipos de jogos que podem ser trabalhados e explorados no ambiente escolar, no entanto, envolvendo a Matemática e a Estatística enfatiza-se os jogos de treinamento e os jogos de estratégia.

Nos jogos de treinamento é preciso que o professor evite o pensamento mecânico do aluno. A construção e a fixação do conceito é um dos objetivos desse tipo de jogo, que quase sempre depende do fator sorte e causa interferência na conclusão dos resultados. A motivação é um fator preponderante para se trabalhar com os jogos de treinamento em sala de aula. O objetivo do jogo deve ser claro para que todos possam compreender melhor a sua finalidade.

Os jogos estratégicos exigem mais atenção e concentração do aluno, pois a todo o momento ele precisa formular e reformular hipóteses, após isso deverá testar, argumentar e verificar sua validade, a fim de descobrir a estratégia para vencer no jogo. Assim, com o intuito de chegar à estratégia vencedora o aluno resolve muitos problemas que surgem após cada lance durante o desenvolvimento do jogo. As jogadas estratégicas exigem do aluno reflexão sobre as consequências de suas decisões durante cada lance do jogo.

A competência e as habilidades que compõem a prática educativa do professor educador estão diretamente relacionadas à sua capacidade de criar diferentes formas de trabalhar em sala de aula. A investigação, a procura, a pesquisa por metodologias de ensino, conhecimentos axiológicos e corporeidade enriquecem a prática do saber fazer no Ensino de Matemática e Estatística no ambiente escolar e auxilia o aluno a relacioná-la com a realidade que o cerca.

\section{CONSIDERAÇÕES FINAIS}

Sabe-se que há muitos desafios a serem superados pelos professores relacionados à sua formação, mas a busca por novos conhecimentos é indispensável. Desta forma, percebe-se que é de extrema importância a conscientização do professor sobre a sua contínua formação, a busca do novo, desenvolvendo sua criatividade e refletindo sobre sua prática educativa e o corpo do aluno, ou seja, a concepção de corporeidade.

Ressalto que a escrita desse texto, tem a finalidade de associar o lúdico, os jogos matemáticos e estatísticos com o corpo do aluno, pois desde do início do curso tenho refletido sobre como posso trabalhar a corporeidade nas aulas de matemática. De acordo com o texto, e as suas citações é notório que alguns autores, como por exemplo Dienes (1975) e Courtney (2006), mesmo não falando explicitamente em corporeidade em seus textos, ele trata os processos dos jogos matemáticos e estatísticos como movimento.

Para Dienes (1975 a), o processo de aprendizagem da matemática acontece gradualmente, a partir da realidade ou do meio em que o aluno se encontra até que este seja capaz de compreender um sistema formal, por meio de símbolos. Por meio de atividades ou jogos concretos é que os alunos do ensino Fundamental serão capazes de desenvolver o conhecimento abstrato. 
A autora Borin (2002), defende que através dos jogos os alunos tornam-se ativos para a construção do seu próprio saber. Assim, os alunos analisam as jogadas, argumentam, criticam, enfim, desenvolve a comunicação, interação, exposição de idéias, reflexão sobre suas atitudes, suas jogadas e as dos colegas.

Os PCN (1997) destacam que os jogos são atividades que despertam nos alunos interesse e prazer e desde que bem elaborado e aplicado os alunos compreendem melhor a utilizar convenções e regras, os quais são indispensáveis no processo de ensino e aprendizagem de Matemática.

Para Courtney (2006), por meio da atividade lúdica e dos jogos o aluno desenvolve sua criatividade. A atividade lúdica e os jogos se tornam reais, pois é ele quem vivencia o imaginado, com suas descobertas, aflições, alegrias, medos, entre outros. $\mathrm{O}$ aluno também desenvolve a socialização, a interação, ética e respeito com todos que o cerca.

Além disso, Lopes (2008) considera importante pensar nos modos pelos quais o ensino de Probabilidade e Estatística podem se inscrever nas práticas pedagógicas contemporâneas. Tal abordagem evidencia que os professores devem possuir o conhecimento daquilo que ensinam em profundidade, para assim, organizá-lo de forma a estabelecer inter-relações entre conteúdo e aprendizado, levando em consideração o desenvolvimento cognitivo, o contexto e os sujeitos a serem ensinados.

Como prática pedagógica para os professores de Matemática e Estatística espera-se ter contribuído com novas perspectivas de um ensino interdisciplinar e contextualizado, visando à motivação e a investigação Matemática e Estatística por meio de novas tecnologias, metodologias de ensino e formação de cidadãos conscientes com pensamentos críticos, reflexivos e responsáveis.

\section{REFERÊNCIA}

Borin, J. (2002). Jogos e resolução de problemas: Uma estratégia para as aulas de matemática (4 ed). São Paulo: IME - Instituto de Matemática e Estatística da USP.

Cazorla, I. M. (2004). Estatística ao alcance de todos. VIII Encontro Nacional de Educação Matemática. Recife 15 a 18 de julho de 2004. Recuperado em jun. 2014: http://www.sbem.com.br/files/viii/pdf/12/MC11915634806.pdf

Courtney, R. (2002). Jogo, teatro e pensamento (3 ed, p. 23). São Paulo: Perspectiva S.A.

Dienes, Z. P. (1975a). As seis etapas do processo de aprendizagem em matemática (M. P. B. de M. Chalier \& R. F. J. Charlier, Trad.). $1^{\text {a }}$ Reimpressão. São Paulo: Editora Pedagógica e Universitária Ltda.

Dienes, Z. P. (1975b). O poder da matemática: Um estudo da transição da fase construtiva para a analitica do pensamento matemático da criança (I. Bicudo, M. A. V. Bicudo \& I. C. Tetzke, Trad.). $1^{\text {a }}$ Reimpressão. São Paulo: Editora Pedagógica e Universitária Ltda.

Gal, I. (2002). Adult's statistical literacy: meanings, components, responsibilities-appeares. Internacional Statistical Review, Espanha, 70(1), 1-33.

Huizinga, J. (1996). Homo ludens: o jogo como elemento da cultura. São Paulo: Perspectiva.

Lopes. C. A. E. (2008). O ensino da estatística e da probabilidade na educação básica e a formação dos professores. Caderno Cedes. 28(74), 57-73.

MEC (1997) Secretaria de Educação Fundamental. Parâmetros curriculares nacionais: Matemática. Brasil.

Mendoza, L.P., \& Swift, J. (1981) Why teach statistics and probability: a rationale. In Shulte, A.P. \& Smart, J.R. (Eds.). Teaching statistics and probability. Reston: Yearbook National Council of Teachers of Mathematics.(p. 90-100).

Moreira, W. W (2014). Corporeidade! Croniquetas 27. Recuperado em: 22 de junho 2014 de http://adm.online.unip.br/img_ead_dp/35421.pdf

Morin, E (2011). Os sete saberes necessário à Educação do futuro (2 ed) Revisada. São Paulo: Cortez; Brasilia, DF: UNESCO.

Nobrega, T. P. (2010). Uma fenomenologia do corpo. São Paulo: Livraria da física.

Onuchic, L. R., \& Allevato, N. S. G. (2009). Trabalhando volume de cilindros através da resolução de problemas. Educação Matemática em Revista - RS, 10(1), 95-103.

Rezende, A. M (1990). de. Concepção fenomenológica da educação. São Paulo: Cortez: Autores Associados. 